This result is further support for the co-ordinate triple link structure ascribed to the other divalent carbon compounds, the iso-cyanides.

L. E. Sutron.

J. Breeze Bentley.

Dyson Perrins Laboratory, Oxford, Aug. 1.

Mond and Nasini, Z. Phys. Chem., 8, 150; 1891.

Sugden," The Parachor and Valeney", London, 1930, p. 189.

3 Ebert, Eisenschitz, and v. Hartel, Z. Phys. Chem., B, 1, 94; 1928.

4 Hammick, New, Sidgwick, and Sutton, J.C.S., $1876 ; 1930$

5 "International Critical Tables ", vol. 6, p. 358.

- "International Critical Tables ", vol. 6, p. 358.

Permann and Tschudnowsky, Z Phys Chem., B 17, 116 . 1932. 8 Hedfeld and Mecke, $Z$. Physik, 64, 151; 1930 . Mecke, ibid., 173 . 1930.

Badger and Binder, Phys. Rev., 37, 800; 1931.

\section{Stereochemistry of Diphenyl}

THE stereochemistry of diphenyl, as was shown in the "Research Items" in NATuRE for April 2, p. 512, in reference to a paper by Prof. R. Kuhn, continues to produce problems of great interest. At a meeting of the Chemical Society held on May 5, a new 'dynamic' effect of groups in the $2: 2^{\prime}$ positions was described. ${ }^{1}$ We have now effected the optical resolution of the monomethiodide of $2: 2^{\prime}$-bisdimethylaminodiphenyl :

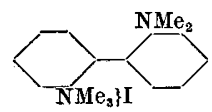

The $d$ - and $l$-methiodides have $[\alpha]_{5791}^{20^{\circ}} \pm 48^{\circ}$ in aqueous solution, in which ionisation is complete, and cold solutions retain their activity for indefinite periods. In aqueous solution at $100^{\circ}$, half-racemisation occurs in just over two hours.

The dissymmetry of the methiodide molecule can only be due to the dynamic effect of the three methyl radicals attached to the nitrogen atom, which, it should be noted, is the smallest atom possessing a tetrahedral configuration. The various implications of our results are being investigated.

F. R. Shaw.

E. E. TURner.

Department of Organic Chemistry,

Bedford College for Women,

University of London, Aug. 5.

${ }^{1}$ Lesslie and Turner, J.C.S., $2021 ; 1932$.

\section{The Ring System of Sterols and Bile Acids}

THE constitutional formula tentatively suggested by Butenand ${ }^{1}$ for the hydrocarbon $\mathrm{C}_{18} \mathrm{H}_{14}$ obtained by him from ketohydroxy-œstrin (follicular hormone) is closely related to the new constitutional formula of sterols and bile acids previously advanced by Rosenheim and King. ${ }^{2}$ The applicability of this formula to the basic ring system of ketohydroxy-œstrin and pregnandiol (see Bernal ${ }^{3}$ ) was, indeed, expressed in our preliminary note, and the work of Marrian and Haslewood ${ }^{4}$ and that of Butenandt (see above) supplies welcome experimental evidence in its favour.

It may be recalled that the essential principle of the formula proposed by ourselves consists in the grouping of three six-membered rings (I., II., and III.) as in phenanthrene, an arrangement which at once permits of a straightforward formulation of those experimental facts, for which the hitherto accepted formula (Windaus-Wieland) afforded no adequate explanation. Chrysene formation from such a ring system can obviously take place whether the attached ring IV. is six- or five-membered (in the latter case by means of the adjoining $\mathrm{CH}_{3}$ group).

In the circumstances it is surely unnecessary for Dr. Butenandt to refer, for " similarities" to the proposed ring system, to papers by Wieland and Windaus which are still " in the press". It may be that these authors will be found to prefer the modification of our formula with a five-membered ring IV., but in the latest available publication from Windaus's laboratory $^{5}$ our formula with a six-membered ring IV. is adopted.

\section{O. ROSENHEIM.} H. KING.

National Institute for Medical Research, London, N.W.3, Aug. 15.

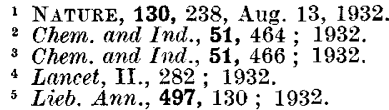

\section{Hall Effect in Beryllium}

I HAVE recently carried out work on the Hall effect in beryllium, by using a plate measuring $1.5 \mathrm{~cm} . \times 1.5 \mathrm{~cm} . \times 0.045 \mathrm{~cm}$., which was prepared, for this purpose, by Siemens and Halske of Berlin, from a sample of pure beryllium $(99.5$ per cent). I made use of Hall's classical experimental arrangement, and measured the e.m.f. by means of a potentiometric method with the use of a very sensitive Siemens and Halske's "Pancergalvanometer".

A large Weiss-type water-cooled magnet (made by Max Hohl of Chemnitz) capable of producing field strengths up to 27,500 gauss in a $4 \mathrm{~mm}$. gap, the pole faces being $15 \mathrm{~mm}$. in diameter, was used.

Many measurements were taken by varying the intensity of the current, and that of the magnetic field up to a maximum of 500 milliamperes and 27,500 gauss respectively.

The effect was very small and positive; the value of the Hall coefficient was found to be +0.0024 \pm 0.0001 .

A detailed account of the experiments will be published shortly.

Physical Institute of the University, Pisa, Italy, July 23.

\section{A. Cicconf.} \section{A.}

$$
\text { No. 3278, VoL. 130] }
$$

